\title{
Impact of porosity on calcination and sulfation of calcium sorbents
}

\author{
Renata Włodarczyk ${ }^{1, *}$, Michat Wichliński ${ }^{1}$ and Zbigniew Bis ${ }^{1}$ \\ ${ }^{1}$ Energy Engineering Department, Faculty of Infrastructure and Environment, Czestochowa \\ University of Technology, Brzeznicka Street 60A, 42-200 Czestochowa, Poland
}

\begin{abstract}
The focus of the study was on sorbents with a grain size of $125-250 \mu \mathrm{m}$. Examinations of reactivity were conducted in a reaction furnace under conditions required for reactivity testing of calcium sorbents. The tests were performed according to standard calcium sorbent tests (FW). Computation of reactivity indices and capacity index were performed according to formulae contained in previous publications [1]. The process of simultaneous calcination and sulfation of calcium sorbents is controlled by the speed of chemical processes and diffusion. Therefore, surface properties of sorbents, including porosity, play an important role in the flue gas desulphurization process. Examinations of sorbent porosity were performed using a mercury porosimeter. Based on porosimetric analysis, open porosity, the total surface area of sorbents and mean diameter of pores were evaluated for the sorbents studied.
\end{abstract}

\section{Introduction}

Calcium sorbents represent a broadly used group of materials for sulphur compounds capture in industrial installations for flue gas desulphurization. In order to remove sulphur compounds, sorbents are introduced to the desulphurization system using wet, partially dry and dry methods [2]. In wet and partially dry methods, sorbent is introduced in the form of suspension, and products are released in dry or wet forms. In wet methods, the flue gas desulphurization product is gypsum. The dry method consists in that the processes of binding sulphur dioxide $\mathrm{SO}_{2}$ occur in the dry state. Chemical processes of sorbent decompositions occur on the porous surface with the creation of calcium oxide $\mathrm{CaO}$ (calcination effect) and then $\mathrm{CaO}$ is bound in the solid form with gaseous sulphur dioxide to calcium sulphate (VI). The layer of calcium salt is obtained on the surfaces of sorbent grains, which might lead to the effect of pore clogging and, therefore, limitation of the places of active reactions of sulfation and slowing down of the process. It is typical of bigger sorbent grains that a non-reacted core of $\mathrm{CaO}$ and the external layer of $\mathrm{CaSO}_{4}$ around the core are formed [3-4].

This study presents the effect of porosity of calcium sorbent, total surface area and size of pores on sorbent reactivity. The examinations were based on calcium sorbents which are commonly used in the energy sector in Poland.

\footnotetext{
${ }^{1}$ Corresponding author: rwlodarczyk@is.pcz.czest.pl
} 
Among various tests that allow for determination of sorbent reactivity, one of the most frequently used is the test used by Alstom and Foster Wheeler (FW test). The FW test consists in initial calcination of sorbent for 30 minutes, followed by sulfation for 60 minutes. Both processes occur with the flow of synthetic flue gas with specific ratios. Two indices that determine the quality of sorbent are obtained during the test. The first is reactivity index (RI, the ratio of calcium moles to sulphur moles $[\mathrm{mol} \mathrm{Ca} / \mathrm{mol} \mathrm{S}]$ ); the second is capacity index (ratio of amount of sulphur bound to the amount of sorbent used $[\mathrm{gS} / \mathrm{kg}$ sorbent]). A high number of tests performed in the study allowed for developing a classification of limestone reactivity [1] (Tab. 1).

Table 1. Classification of limestone reactivity by FW test [1].

\begin{tabular}{|c|c|c|}
\hline Classification & $\begin{array}{c}\text { Reactivity index RI Ca/S } \\
\text { [mol/mol] }\end{array}$ & $\begin{array}{c}\text { Capacity index CI } \\
\text { [gS / kg sorbent] }\end{array}$ \\
\hline Perfect & $<2.5$ & $>120$ \\
\hline Good & $2.5-3.0$ & $100-120$ \\
\hline Medium & $3.0-4.0$ & $80-100$ \\
\hline Sufficient & $4.0-5.0$ & $60-80$ \\
\hline Poor & $5.0<$ & $<60$ \\
\hline
\end{tabular}

\section{Materials and methods}

\subsection{Materials}

Examinations concerned eight samples of sorbents: S1; S2; S3, S4, S5, S6, S7, S8 with a grain size of $125-250 \mu \mathrm{m}$. Sorbent reactivity was examined according to the recommendations for the FW test. All the sorbent samples originate from Polish mines of limestone.

\subsection{Methods}

\subsubsection{Examinations of calcium sorbent reactivity: research stand}

Examinations are performed on a research stand that represented the equipment of the Department of Energy Engineering.

The design and organization of gas flow allowed for tracking and recording changes in the sorbent sample mass undisturbed by the flow of gases. The basic part of the research stand is an airtight laboratory furnace (electrically heated, power of heaters: 1.8) that allows for maintaining the interior temperature of up to $1100^{\circ} \mathrm{C}$. Accuracy of temperature control is $\pm 10^{\circ} \mathrm{C}$. Furnace chamber length is $220 \mathrm{~mm}$, with diameter of $110 \mathrm{~mm}$.

Synthetic flue gas was supplied to the furnace interior, with its composition chosen and maintained during the measurement at a specific level, using automatic $\mathrm{O}_{2}, \mathrm{CO}_{2}$ and $\mathrm{SO}_{2}$ controllers. The flow rate for synthetic flue gas was $10 \mathrm{l} / \mathrm{min}$. The examinations were conducted for the concentration of gas consistent with the reactivity test of calcium sorbents used by Alstom and Foster Wheeler.

Before introduction to the furnace, flue gas components were initially mixed in the mixer. Sorbents tested had the initial mass of $0.1 \pm 0.02 \mathrm{~g}$. A sample with selected grain size of 125-250 $\mu \mathrm{m}$ was placed on the arm of electronic scales (see Fig. 1). The arm tip had a dedicated net made of nickel, which was the support for the cuboid of the porous glass cotton, $\mathrm{Al}_{2} \mathrm{O}_{3}$ (Sibral $\left.{ }^{\circledR}\right)$. The use of $\mathrm{Al}_{2} \mathrm{O}_{3}$ with high porosity was aimed to ensure a high degree of dispersion of sorbent grains in order to eliminate limitations in the access to gaseous substrates on the grain surface during reaction and outflow of product (e.g. $\left.\mathrm{CO}_{2}\right)$. 
After placing the swab with the sample on the arm of the scales, it was inserted into the furnace heated to a specific temperature (usually $850^{\circ} \mathrm{C}$ ). The sample was put in the reactor by moving the furnace on the wheeled system. A thermocouple was installed near the sample in order to monitor process temperature. Flue gas was introduced to the environment using the exhaust pipe. Indications of the measurement instruments were saved in the PC using the analog-digital converter. A diagram of the test stand is presented in Fig. 1.

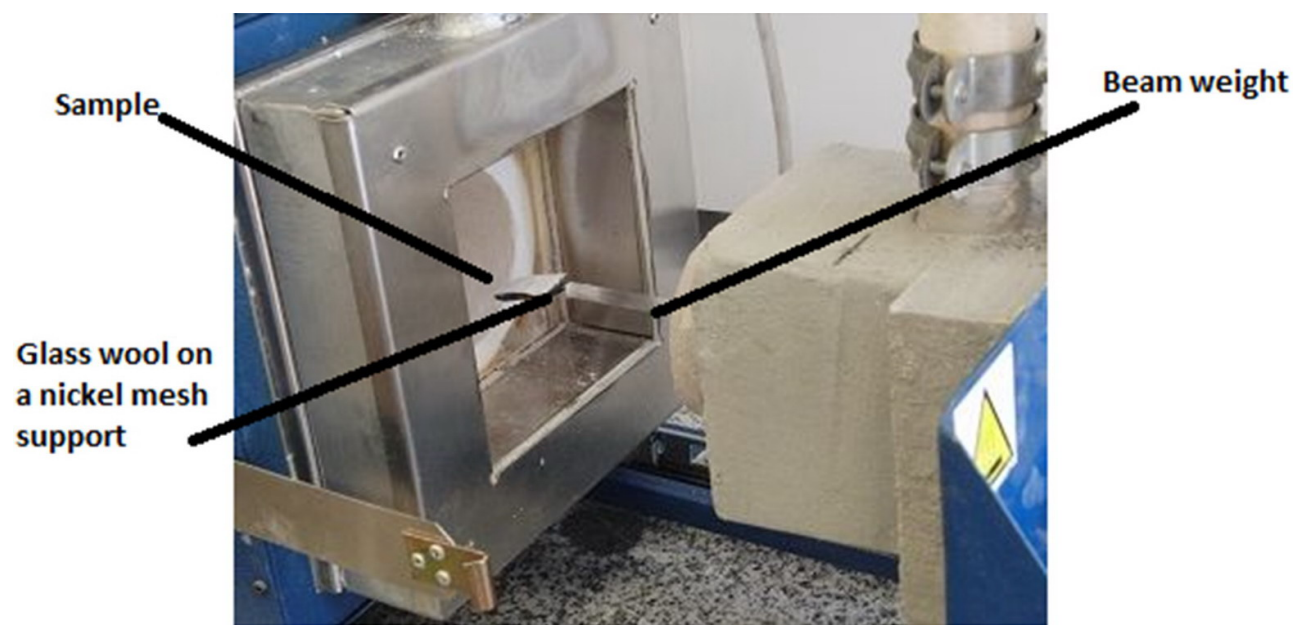

Fig. 1. Laboratory stand for sorbent examinations with a horizontal gas flow.

\subsubsection{Examinations of calcium sorbent reactivity}

The reactivity index was determined by taking into consideration the purity of sorbent used in the study, which was determined based on mass reduction during sample ignition. The RI index was evaluated based on the formula (1):

$$
R I=\frac{m_{p} \cdot \eta \cdot C_{C a} \cdot M_{S}}{M_{C a} \cdot m_{k} \cdot S_{K} \cdot 100}=\left[\frac{\mathrm{molCa}}{\mathrm{mol} S}\right]
$$

where: $\mathrm{m}_{\mathrm{p}}$ - initial mass, $\mathrm{g}$,

$\eta$ - content of $\mathrm{CaCO}_{3}$ in limestone, $\mathrm{g} \mathrm{CaCO}_{3} / \mathrm{g}$,

$\mathrm{C}_{\mathrm{Ca}}$ - content of $\mathrm{Ca}$ in $\mathrm{CaCO}_{3}, \%$

$\mathrm{M}_{\mathrm{S}}-$ molar mass of sulphur, $\mathrm{g} / \mathrm{mol}$,

$\mathrm{M}_{\mathrm{Ca}}$ - molar mass of calcium, $\mathrm{g} / \mathrm{mol}$,

$\mathrm{m}_{\mathrm{k}}$ - final mass, $\mathrm{g}$,

$\mathrm{S}_{\mathrm{K}}$ - content of sulphur in the final sample, $\%$.

Capacity index CI was determined from the formula (2):

$$
C I=\frac{m_{k} \cdot S_{K} \cdot 10}{m_{p}}=\left[\frac{g S}{k g_{\text {sorbentu }}}\right]
$$

where: $\mathrm{m}_{\mathrm{k}}-$ final mass, $\mathrm{g}$,

$\mathrm{S}_{\mathrm{K}}-$ content of sulphur in the final sample, $\%$.

$\mathrm{m}_{\mathrm{p}}-$ initial mass, $\mathrm{g}$.

The content of final sulphur was determined by means of the LECO CHNS TruSpec analyser. 


\subsubsection{Porosimetric examinations using a mercury porosimeter}

The analysis of porosity was performed by means of the PoroMaster 33 mercury porosimeter with Quantachrome Instruments for Windows software to evaluate the effect of porosity of sorbents on the effectiveness of flue gas desulphurization using a specific sorbent, Examinations using the mercury porosimeter were performed three times for each sample of sorbents.

\section{Results and discussion}

\subsection{Sorbent reactivity}

The results of reactivity tests for individual sorbents are presented in Table 2. For the FW test and the fraction of $125-250 \mathrm{~m}$, the highest value of reactivity index RI was obtained for sorbent samples S4 - $2.59 \mathrm{~mol} / \mathrm{mol}$, and S2 and S5, with 2.72 and $2.74 \mathrm{~mol} / \mathrm{mol}$, respectively. Results of capacity index CI are consistent with those obtained for reactivity index, which results directly from (1) and (2), therefore the lower the value of reactivity index, the higher the value of capacity index CI. Within the classification of sorbents presented in Table 1, only sorbents S2, S3, S4, S5 would be qualified as very good, whereas sorbents S1, S6, S7, S8 can be considered good.

Table. 2 Values of reactivity index and specific sorption obtained for individual sorbents.

\begin{tabular}{|c|c|c|c|c|}
\hline Sorbent & Fraction & Test & RI [mol Ca/mol S] & CI [g S/kg sorbent] \\
\hline S1 & $125-250$ & FW & 3.04 & 105.11 \\
\hline S2 & $125-250$ & FW & 2.72 & 114.88 \\
\hline S3 & $125-250$ & FW & 2.86 & 109.35 \\
\hline S4 & $125-250$ & FW & 2.59 & 119.02 \\
\hline S5 & $125-250$ & FW & 2.74 & 112.82 \\
\hline S6 & $125-250$ & FW & 3.53 & 86.07 \\
\hline S7 & $125-250$ & FW & 3.57 & 85.17 \\
\hline S8 & $125-250$ & FW & 3.65 & 84.27 \\
\hline
\end{tabular}

Since values of RI and CI indices are based on the same data (initial mass, final mass and content of final sulphur), the latter part of the paper focused on the comparison of only the reactivity index RI with values obtained from the porosimetric examinations.

Fig. 2 presents the relationships between the reactivity index computed for the FW test and total surface area. It can be observed that for S4, which had the best reactivity index $(2.59 \mathrm{~mol} / \mathrm{mol})$, total surface area was also the highest $\left(1.5 \mathrm{~m}^{2} / \mathrm{g}\right)$. Similar high value of total surface area was observed for S2 and S4 sorbents (over $1 \mathrm{~m}^{2} / \mathrm{g}$ for all cases). In the case of S1, S6, S7 and S8, the reactivity index was over $3 \mathrm{~mol} / \mathrm{mol}$, which is attributable to a low value of total surface area of $1 \mathrm{~m}^{2} / \mathrm{g}$. With $\mathrm{S} 3$, total surface area, which was below $1 \mathrm{~m}^{2} / \mathrm{g}$, did not prevent it from reaching a very high RI of $2.86 \mathrm{~mol} / \mathrm{mol}$. This is most likely caused by a specific chemical composition of sorbent and the shape and value of pores, reflected by a high porosity of $8.9 \%$. The lowest value of total surface area was documented for the $\mathrm{S} 7$ sorbent $\left(0.43 \mathrm{~m}^{2} / \mathrm{g}\right)$. Also for this sorbent, the reactivity index (RI) was one of the poorest $(3.57 \mathrm{~mol} / \mathrm{mol})$. 
Q RI Total Surface Area $[\mathrm{m} 2 / \mathrm{g}]$

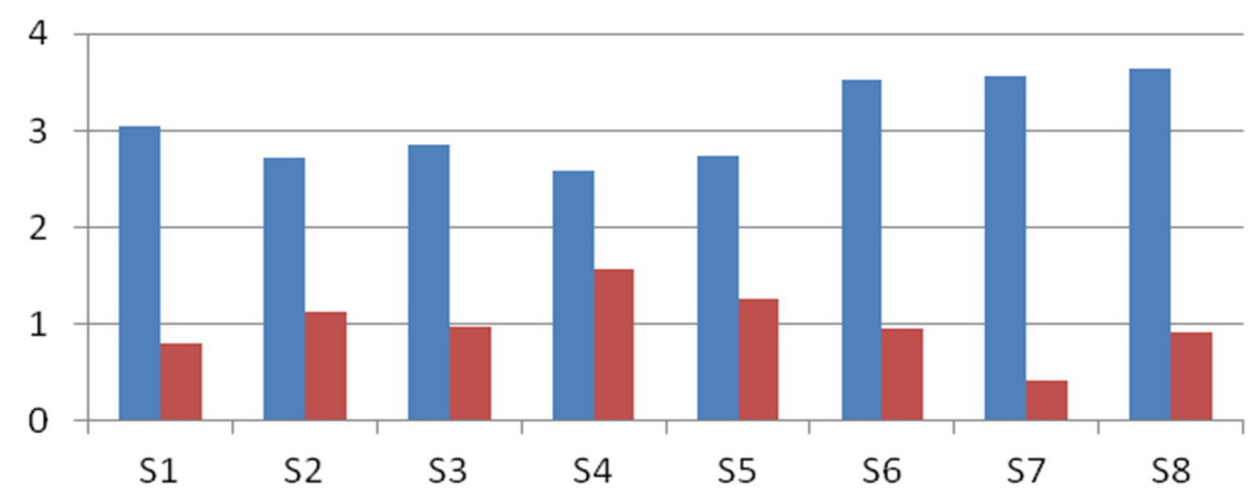

Fig. 2. Reactivity of sorbents determined using the FW method depending on total surface area of sorbents.

Considering the comparison of the reactivity indices for sorbents and total porosity for the sample leads to the conclusion that for S4, which had the best RI $(2.59 \mathrm{~mol} / \mathrm{mol})$, total porosity was also at one of the highest levels (ca. 7.8\%). Higher values of total porosity were reached by two sorbent samples (S3 and S5, with 8.9 and $8.7 \%$, respectively). In the case of these sorbents, the RI was below $3(2.86 \mathrm{~mol} / \mathrm{mol}$ for S3 and $2.74 \mathrm{~mol} / \mathrm{mol}$ for S5). Furthermore, a very low porosity of the S6, S7 and S8 sorbents as well as S1 led to poor results in the FW test, where all these samples obtained a value of RI over $3 \mathrm{~mol} / \mathrm{mol}$ (Fig. 3).

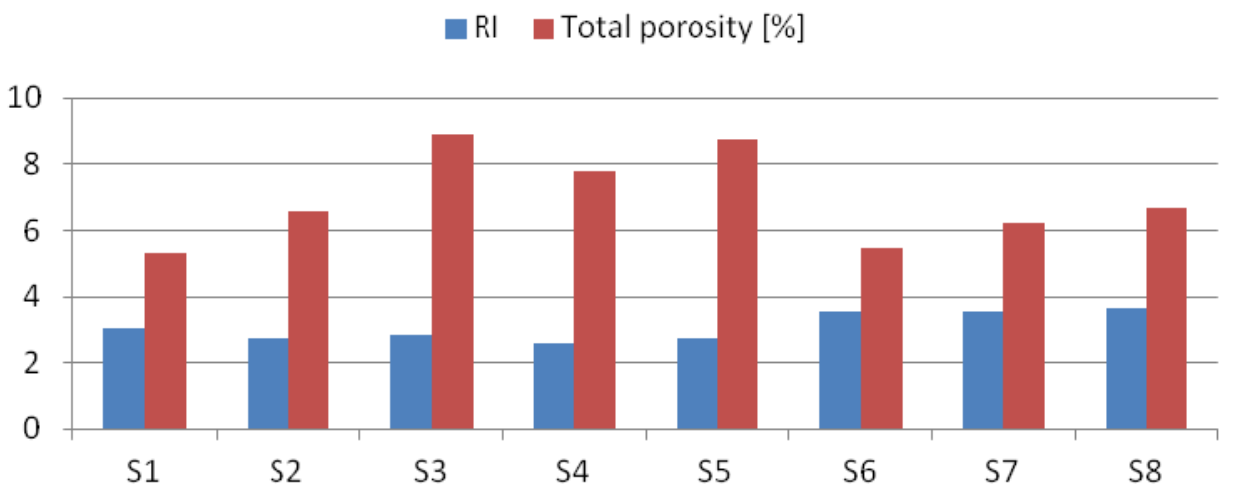

Fig. 3. Reactivity of sorbents determined using the FW method depending on total porosity of sorbents.

\subsection{Porosity and total surface area of sorbents}

Table 1 presents value of parameters evaluated for the sorbents of the 125-250 $\mu \mathrm{m}$ fraction. Total surface area and open porosity was determined by means of porosimetric examinations using a mercury porosimeter. Degree of surface area development (total surface area) for the sorbents ranged from $0.4272 \mathrm{~m}^{2} \mathrm{~g}^{-1}$ for $\mathrm{S} 7$ to $1.5764 \mathrm{~m}^{2} / \mathrm{g}$ for S4. Values of open porosity ranged from $6.2 \%$ to $8.9 \%$ (for S7 and S3, respectively). As results from the data contained in Fig. 1 and Fig. 2 show, a positive effect on the RI index is from open porosity: the higher the open porosity, the higher the RI index determined by means of the FW method. Open sorbent pores facilitate the process of initial sorbent calcination, followed by sulfation through mechanical processing of the sorbents before use [5-6]. 
Table 3. Porosity and total surface area determined by the sorbents studied.

\begin{tabular}{|c|c|c|c|}
\hline Sorbent & Fraction & $\begin{array}{c}\text { Total Surface Area } \\
{\left[\mathbf{m}^{\mathbf{2}} \mathbf{g}\right]}\end{array}$ & $\begin{array}{c}\text { Total porosity } \\
{[\mathbf{\%}]}\end{array}$ \\
\hline S1 & $125-250$ & 0.7944 & 5.2958 \\
\hline S2 & $125-250$ & 1.1364 & 6.5738 \\
\hline S3 & $125-250$ & 0.9799 & 8.9073 \\
\hline S4 & $125-250$ & 1.5764 & 7.8123 \\
\hline S5 & $125-250$ & 1.2686 & 8.7361 \\
\hline S6 & $125-250$ & 0.9477 & 5.4548 \\
\hline S7 & $125-250$ & 0.4272 & 6.2022 \\
\hline S8 & $125-250$ & 0.9266 & 6.6788 \\
\hline
\end{tabular}

Degree of the use of sorbent for desulphurization depends on the chemical composition of sorbent and, as results from the data contained in Tabs. 1-3, surface porosity. Calcination process leads to the release of $\mathrm{CO}_{2}$ from calcium carbonate, which causes formation of a porous product, i.e. $\mathrm{CaO}$. With high temperature, $\mathrm{CaO}$ can become sintered and form eutectics with sorbent pollutants [7]. Presence of pollutants (additives) in the sorbent impacts the sulfation process. According to Fuertes and Fernandez [11], additives, mostly in the form of carbonates, elevate reactivity of sorbents in the following order (the compounds which occur most frequently in sorbents):

$$
\mathrm{Na}_{2} \mathrm{CO}_{3}>\mathrm{Li}_{2} \mathrm{CO}_{3}>\mathrm{K}_{2} \mathrm{CO}_{3}>>\mathrm{Na}_{2} \mathrm{SO}_{4}>\ldots .>\mathrm{NaCl}>\ldots .>\mathrm{Al}_{2}\left(\mathrm{SO}_{4}\right)_{3} .
$$

Calcination processes followed by sulfation occur on the sorbent surface (at the boundary between the solid and gaseous phases). Therefore, porosity of the materials is critical. According to the classification introduced by IUPAC (International Union of Pure and Applied Chemistry), there are three basic classes of pores [8]: micropores (with diameter of $<0.002 \mu \mathrm{m}$ ), mesopores (with diameter of $0.002-0.050 \mu \mathrm{m}$ ) and macropores (with diameter of $>0.050 \mu \mathrm{m}$ ). Micro- and mesopores are critical to adsorption processes and determine the magnitude of the internal surface. Macropores perform the role of routes of transport, providing access to pores with smaller sizes. Fig. 4 presents distribution functions of total surface area for the sorbents studied. The highest value of total surface

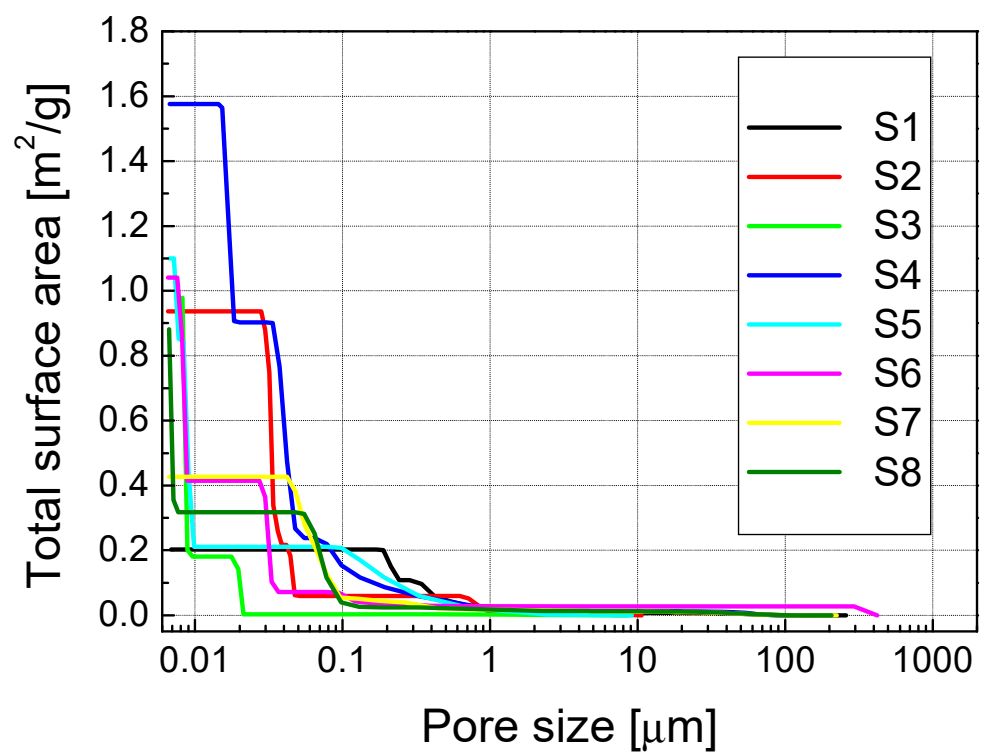

Fig. 4. Distribution function of total surface area for selected sorbents. 
area was observed for S2, S3, S4, S5, S6, S8. These results are correlated with the data presenting distribution of pores depending on their diameter (Fig. 5). The high value of total surface area is largely affected by the presence of pores from the classes of micro- and mesopores. For the S7 sample, where a high percentage of pores from the mesopore class and the macropore class is observed, without pores with a diameter below $0.002 \mu \mathrm{m}$, the value of total surface area is $0.4272 \mathrm{~m}^{2} / \mathrm{g}$ and is the lowest among the samples studied. The S8 sample shows a percentage of macropores, but a high percentage of micropores is also observed. Consequently, the total surface area evaluated for S8 is high compared to other samples $\left(0.9266 \mathrm{~m}^{2} / \mathrm{g}\right)$.

The results evaluated for the S3 sample seem to be interesting: despite low total surface area compared to other samples (below $1 \mathrm{~m}^{2} / \mathrm{g}$ ) the RI coefficient was high, at $2.86 \mathrm{~mol} / \mathrm{mol}$. Fig. 6 compares histograms of pore diameter distribution in S4 (high total surface area and high RI) with S3. The S3 sorbent is characterized by a high percentage of macropores (which ensures a high open porosity) and minimal percentage of meso- and micropores.

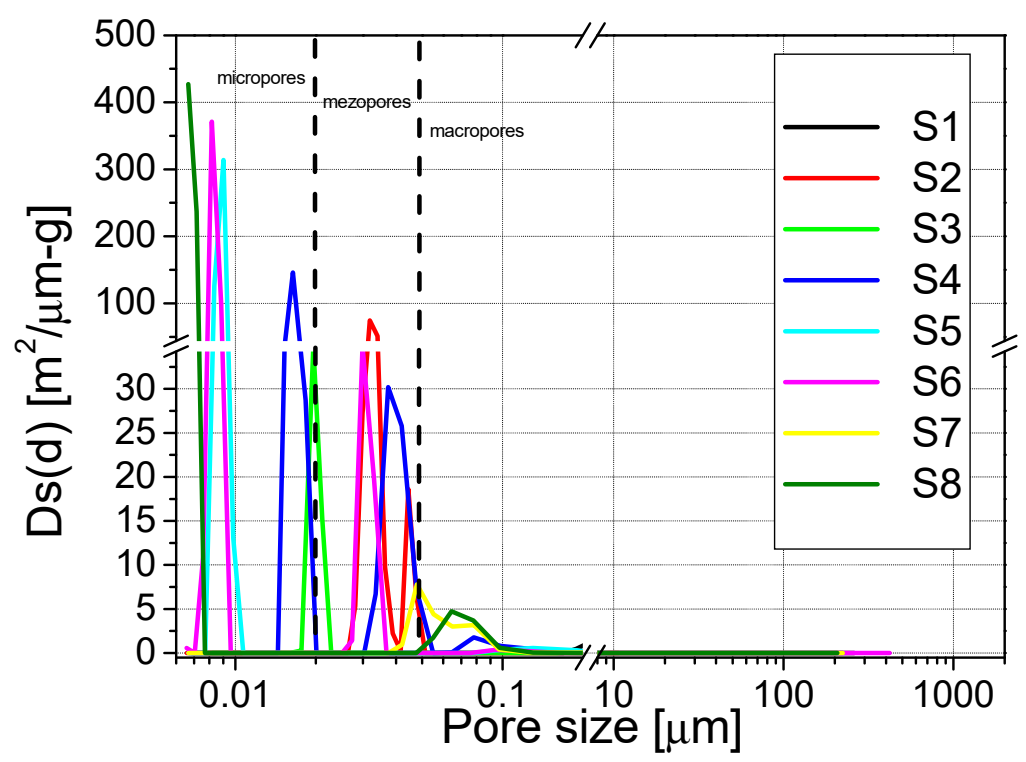

Fig. 5. Distribution function of unit pore diameter for selected sorbents.
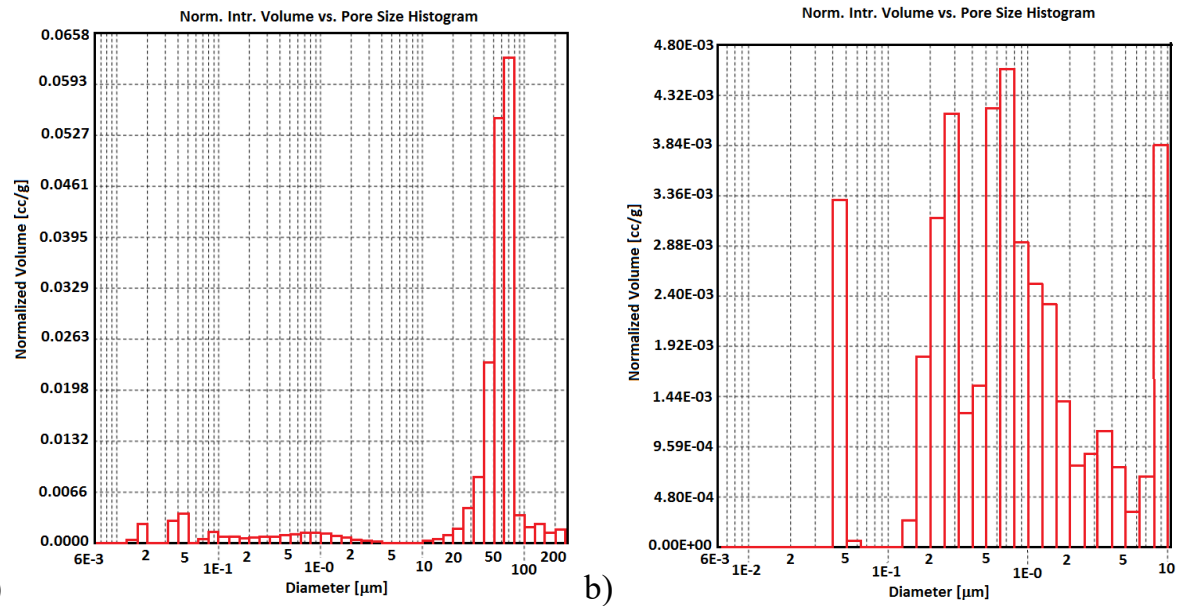

Fig. 6. Normalized introduction volume versus pore size histogram of a) S4 sorbent; b) S3 sorbent. 


\section{Conclusions}

Examinations of calcium sorbent reactivity were performed by means of the FW method using the same grain size $(125-250 \mu \mathrm{m})$. The examinations allowed for determination of the reactivity index (RI) and capacity index (CI). A mercury porosimeter was employed to evaluate total surface area and open porosity of calcium sorbents. The results of the examinations and analyses lead to the following conclusions:

- values of capacity index CI are consistent with those obtained for reactivity index; therefore the lower value of reactivity index RI, the higher value of capacity index CI.

- with classification of sorbents according to FW test, only sorbents S2, S3, S4, S5 were considered as very good, whereas sorbents S1, S6, S7, S8 were good;

- the $\mathrm{S} 4$ sorbent, with the best reactivity ratio $(2.59 \mathrm{~mol} / \mathrm{mol})$ among the samples studied is characterized by the highest value of total surface area of ca. $1.5 \mathrm{~m}^{2} / \mathrm{g}$;

- with S3, total surface area, which was below $1 \mathrm{~m}^{2} / \mathrm{g}$, did not prevent from reaching a very high RI of $2.86 \mathrm{~mol} / \mathrm{mol}$. This is most likely caused by a specific chemical composition of sorbent and the shape and value of pores, reflected by high porosity of $8.9 \%$;

- the process of initial sorbent calcination, followed by sulfation (the FW test) using sorbents of $125-250 \mu \mathrm{m}$ fraction, is substantially controlled by the total surface area, especially the percentage of pores with diameter $<0.002 \mu \mathrm{m}$, i.e. micropores.

The research was financed by grants No.BS/PB-404-301/11.

\section{References}

1. M. Olas, Reaktywność sorbentów wapniowych poddanych mechanicznej aktywacji, (Rozprawa doktorska, Politechnika Częstochowska, 2006)

2. G. Hu, K. Dam-Johansen, S. Wedel, J.P. Hansen, Prog. Energy Comb. Sci, Review, 32, 386-382 (2006)

3. R. Kobyłecki, R. Włodarczyk, M. Wichliński, Z. Bis, Effect of mechanical treatment on the reactivity of a limestone sorbent, monography, Sorbenty Mineralne - surowce, energetyka, ochrona środowiska, nowoczesne technologie, (T. Ratajczak, G. Rzepa, T. Bajda (Eds.), wyd. AGH, 225-233, ISBN 978-83-7464-629-1, Kraków 2013)

4. J. Abbasian, A. Rehmat, D.D. Banerjee, Industrial \& Engineering Chemistry Research 30, 1990-1994 (1991)

5. F. Montagnaro, P. Salatino, F. Scala, Experimental Thermal and Fluid Science, 34, 352-358 (2010)

6. G.H. Newton, S.L. Chen, J.C. Kramlich, AICHE Journal, 35, 988-994 (1989)

7. A.B. Fuertes, M.J. Fernandez, Thermochimica Acta, 276, 257-263 (1996)

8. www.iupac.org (April 2018)

9. D. Riegert, K. Radwan, J. Rakowska, A. Miazga, Cer. Mat., 68, 22-27 (2016)

10. B. Walawska, A. Pajdak, Przemysł chemiczny, DOI:10.15199/62.2016.6.20. 